\title{
Düşük ejeksiyon fraksiyonlu kalp yetersizliği, atriyal fibrilasyon ve natriüretik peptidler: retrospektif kapalı kohort verileri
}

\author{
Heart failure with reduced ejection fraction, atrial fibrillation and natriuretic peptides: \\ retrospective data from a closed cohort
}

Ebru İpek Türkoğlu, Emine Çiğdem Kırçiçeği Çiçekdağ

Gönderilme tarihi: 18.11.2019

Kabul tarihi: 20.12.2019

\section{Özet}

Amaç: Düşük ejeksiyon fraksiyonlu kalp yetersizliği (DEF-KY), kalp yetersizliği (KY) kliniği ile birlikte sol ventrikül ejeksiyon fraksiyonunun (SoVEF) $<40$ olması olarak tanımlanır ve bu grupta eşlik eden atriyal fibrilasyon (AF) daha kötü bir prognozla birliktedir. Biz bu çalışmamızda, kendi kohortumuzda bulunan DEF-KY ve AF hastalarının özelliklerini ve NT-proBNP düzeylerini incelemeyi amaçladık.

Gereç ve yöntem: Çalışmaya Ocak-Haziran 2018 tarihleri arasında İzmir Kemalpaşa Devlet Hastanesi Kardiyoloji Polikliniği'ne başvuran SoVEF $<\% 40$ olan AF eşlik eden ve kompanse KY fazında en az bir kere NTproBNP değeri bulunan ayaktan hastalar çalışmaya alındı. Hastaların bazal özellikleri ile stabil ve dekompanse fazdaki NT-proBNP düzeyleri araştırıldı.

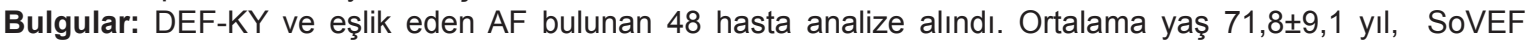
$\% 35,9 \pm 2,3$, CHA2DS2 ve CHA2DS2VASc skorları sırasıyla 3,3 $\pm 1,3$ ve 4,8 $\pm 1,4$ idi. Stabil fazdaki medyan NTproBNP 2039,50 pg/ml bulundu. Dekompanse fazda NT-proBNP, 15 hastada mevcuttu ve medyan 3093 pg/ ml $($ artış \%91,34) idi. NT-proBNP düzeyindeki değişim ne CHA2DS2 ne de CHA2DS2VASc skorları ile korele değildi.

Sonuç: Natriüretik peptidlerin KY tanısındaki önemi bilinmektedir ancak her ne kadar AF varlığında daha yüksek olduklarına dair temel bir bilgi olsa da AF ile birlikte olan DEF-KY hasta grubunda üst sınırlar bilinmemektedir. Bu çalışma, AF olan DEF-KY hastalarında stabil fazdaki NT-proBNP düzeyinin sinüs ritminde önerilen üst sınırların çok üstünde olduğunu ve bazal değerlere göre minimum $\% 40,7$ artışın dekompansasyon ile ilişkili olduğunu göstermiştir. Çalışmamız, AF olan DEF-KY hastalarında kompanse fazdaki NT-proBNP'nin bilinmesinin bireyselleştirilmiş tedavinin bir parçası olarak dekompansasyon tanısı için önemini vurgulamaktadır.

Anahtar kelimeler: Atriyal fibrilasyon, düşük ejeksiyon fraksiyonlu kalp yetersizliği, NT-proBNP.

Türkoğlu El, Kırçiçeği Çiçekdağ EÇ. Düşük ejeksiyon fraksiyonlu kalp yetersizliği, atriyal fibrilasyon ve natriüretik peptidler: retrospektif kapalı kohort verileri Pam Tıp Derg 2020;13:155-162.

\begin{abstract}
Purpose:Heart failure with reduced ejection fraction (HFrEF) is defined as clinical heart failure (HF) when the left ventricle ejection fraction (LVEF) is less than $40 \%$. Concomitant atrial fibrilation (AF) is associated with worse prognosis in this group and N-terminal-pro B type natriuretic peptide (NT-proBNP) levels are not widely investigated. In the present study, we aimed to investigate patients in a closed cohort with HFrEF and AF and their NT-proBNP levels.

Materials and methods: Data of patients who applied to the cardiology outpatient clinic of Izmir Kemalpasa State Hospital between January and June 2018 is reviewed retrospectively. Patients who diagnosed with AF and HF with LVEF $<40 \%$ and NT-proBNP level in stable phase of chronic HF are included to the study. Demographics of patients with HFrEF and AF and their NT-proBNP levels are investigated.

Results: According to the inclusion criteria, 48 patients were enrolled to the study. Mean age, LVEF, CHA2DS2 and CHA2DS2VASc scores were $71.8 \pm 9.1$ years, $35.9 \pm 2.3 \%, 3.3 \pm 1.3$ and $4.8 \pm 1.4$ respectively. Median NTproBNP level in stable chronic phase of HF was $2039.50 \mathrm{pg} / \mathrm{ml}$. NT-proBNP level in decompansated phase of HF was present in 15 patients and the median level and the change of NT-pro BNP were $3093 \mathrm{pg} / \mathrm{ml}$ and $91.34 \%$ respectively. There was no correlation between the change of NT-proBNP level and CHA2DS2 or CHA2DS2VASc scores.

Conclusion: The clinical value of NT-proBNP in the HF is well known. AF is another condition which may cause higher levels. Although higher levels of NT-proBNP are expected with the co-presence of HFrEF and AF, the upper limit is not known. The knowlegde of the NT-proBNP level in stable chronic HFrEF and AF patient may help for the diagnosis of decompansation in part of individualised treatment.
\end{abstract}

Ebru İpek Türkoğlu, Uzm. Dr. İzmir Kemalpaşa Devlet Hastanesi Kardiyoloji Kliniği, IZMiR, e-posta: dripek73@yahoo.com, cigdemcicekdag@ hotmail.com (orcid.org/0000-0002-2321-8868) (Sorumlu Yazar)

Emine Çiğdem Kırçiçeği Çiçekdağ, Uzm. Dr. Kemalpaşa Devlet Hastanesi Anesteziyoloji ve Reanimasyon Kliniği, IZMiR, e-posta: cigdemcicekdag@hotmail.com (orcid.org/0000-0002-2356-1420) 
Key words: Atrial fibrillation, heart failure with reduced ejection fraction, NT-proBNP.

Türkoğlu EI, Kırçiçeği Çiçekdağ EÇ. Heart failure with reduced ejection fraction, atrial fibrillation and natriuretic peptides: retrospective data from a closed cohort. Pam Med J 2020;13:155-162.

\section{Giriş}

Kalp yetersizliği (KY), yapısal veya fonksiyonel bir kardiyak anomali varlığında, azalmış kardiyak debi veya artmış intrakardiyak basınca bağlı gelişen, tipik semptomları olan klinik bir sendromdur. Son Avrupa KY kılavuzu, KY tanımını nefes darlığı, yorgunluk, ayaklarda şişme gibi klinik semptomların varlığı ile sınırlamıştır. Klinik semptomların olmaması durumunda tanım, sistolik veya diyastolik sol ventrikül disfonksiyonu olarak belirlenmiştir. Son kılavuz ayrıca KY terminolojisinde düşük ejeksiyon fraksiyonlu (DEF), orta seviyede ve korunmuş ejeksiyon fraksiyonlu (KEF) KY tanımlarını getirmiştir. Bir süredir $K Y$ olan hastalar, 'kronik' $K Y$ olarak, en az 1 aydır semptom ve bulguları değişmeden kalan hastalar, 'stabil' olarak ve kronik-stabil fazda seyrederken KY kötüleşen hastalar, 'dekompanse' olarak tanımlanır. Dekompansasyon ani olabildiği gibi yavaşça da olabilir [1]. KY hastalarında semptomların ciddiyeti ile sağkalım arasında açık bir ilişki vardır [1-4]. Hospitalize edilen hastalarla ilgili son veriler DEF-KY insidansında bir azalma düşündürmektedir $[1,5,6]$. Son yıllarda tedavideki gelişmeler, DEF-KY hastalarında sağkalımı arttırmış ve hospitalizasyonu azaltmıştır. En son Avrupa verileri, DEF-KY için 12-aylık tüm sebepli mortalite oranını hospitalize hastalarda $\% 17$, stabil/ayaktan hastalarda $\% 7$ olarak vermektedir. ESC-HF çalışmasında, stabil hastalarda 12 aylık hospitalizasyon oranı \%32 bulunmuştur. Tüm sebepli mortalite DEF-KY grubunda KEF-KY grubuna göre daha yüksektir [1, 7]. Atriyal fibrilasyon (AF), SoVEF'den bağımsız olarak tüm $\mathrm{KY}$ gruplarında en sık görülen ritm bozukluğudur ve kardiyak fonksiyonları daha da bozarak $\mathrm{KY}$ semptomlarında kötüleşmeye yol açar [8]. Her ne kadar ileri yaş ve KY ciddiyeti etkili olsa da kronik KY ve kalıcı AF olan hastaların prognozu, sinüs ritminde olanlardan kötüdür [1, 9, 10]. Natriüretik peptidler (NP), standart yöntemlere göre $\mathrm{KY}$ tanısında oldukça yüksek bir tanısal doğruluk oranına sahiptir [11]. KY için kantitatif bir belirteç olan NP, sürekli bir değişken olarak değerlendirilmelidir. Düşük NP düzeyleri KY dışlamada yüksek bir negatif prediktif değere sahipken, yüksek düzeyler varlığında dispnenin $K Y$ ile ilişkili olduğu düşünülmelidir. Ancak, her ne kadar mortalite ilişkisi devam etse de NP'nin kalp dışı sebeplerle (kritik hastalık, sepsis vb) de yükselebileceği bilinmelidir. Son Avrupa NP kılavuzu, NT-proBNP için akut dispneyle başvuran hastalarda kalp yetersizliği tanısında yaşa göre $<50,50-75$ ve $>75$ yıl için sırasıyla 450,900 ve 1800 pg/ml değerlerini önermektedir. Akut olmayan durumlarda her yaş grubu için NT-proBNP $>600 \mathrm{Pg} / \mathrm{ml}, \quad \mathrm{KY}$ düşündürmelidir [11-13]. KY ve AF varlığında NP değerlendirmek hiç kolay değildir, çünkü $A F$, daha yüksek NP düzeyleri ile ilişkilidir, hatta tanı için ek bulgusu olmayan bazı hastalarda NP düzeyleri KY için tanısal üst sınır değerlerini geçebilir ve klinik karar vermede zorluklar oluşabilir [11, 14]. Biz bu çalışmada kendi kohortumuzdaki DEF-KY ve AF olan hastaların özelliklerini ve NT-proBNP düzeylerindeki değişimi araştırmayı amaçladık.

\section{Gereç ve yöntem}

İzmir Kemalpaşa Devlet Hastanesi Kardiyoloji Kliniği'ne Ocak-Haziran 2018 tarihleri arasında ayaktan başvuran hastalar, retrospektif olarak hastane bilgi yönetim sistemi (HBYS) üzerinden tarandı. Tanı olarak AF ve KY tanılarıyla takip edilen ve SoVEF $<\% 40$ olan hastalar bulundu. Bu hastalardan sadece stabil kronik fazda NT-proBNP bakılan 48 hasta çalışmaya alındı. Protez kalp kapağı, ciddi mitral darlık, diyaliz gerektiren kronik böbrek yetmezliği hastaları dışlandı. Hastaların geliş şikayetleri, EKG, ekokardiyografi, laboratuvar sonuçları ve kullandıkları ilaçlar HBYS üzerinden bulundu. Kurum, $>100,000$ nüfuslu bir popülasyona sahip kapalı bir kohortun tek sağlık kurumu olduğu için ve hastaların çoğu çalışma döneminden önce de kliniğin takibinde olduğundan, takipte hastaların nasıl değişim gösterdiği araştırıldı. Hastaların EKG'leri HBYS üzerinden görüntülendi. Hastanedeki ekokardiyografi cihazı, Philips Affiniti 50C idi ve tüm incelemeler bu cihazla yapıldı. NP olarak hastanede daha stabil profil nedeniyle NT- 
proBNP kullanılmaktaydı ve ölçümleri Roche Diagnostics $\mathrm{GmbH}$ 'den Elecsys proBNP II kullanan Cobas ${ }^{\circledR}$ sistemi ile yapıldı.

Istatistiksel analizde normal dağılan devamlı değişkenler ortalama \pm standart sapma olarak, normal dağılmayan devamlı değişkenler median, minimum ve maksimum olarak ve kategorik değişkenler ise sıklık ve yüzdeler ile verildi. $P$ değeri $<0,05$ istatistiksel olarak anlamlı kabul edildi. Değişkenler arasındaki ilişki Pearson's korelasyon testi ile bakıldı. $R$ değeri - negatif yönde, + pozitif yönde, 0,01-0,29=zayıf, 0,30$0,69=$ orta düzeyli ve $0,70-0,99=$ güçlü ilişki göstergesi olarak kabul edildi. Analizler için IBM SPSS-22 kullanıldı.

Çalışmanın etik onamı, Sağlık Bilimleri Üniversitesi İzmir Tepecik Sağlık Uygulama Araştırma Merkezi Girişimsel Olmayan Etik Kurulundan 14.11.2018 tarihinde alındı.

\section{Bulgular}

Çalışmaya alım kriterleri uygulandıktan sonra $\mathrm{KY}$ ve $\mathrm{AF}$ tanısı olan ve SoVEF $<\% 40$ bulunan 48 hasta analize alındı. Bu hastaların HBYS üzerinden anamnez ve laboratuvar geçmişleri araştırılarak ne süredir kliniğin takibinde oldukları ve önceki laboratuvar parametreleri bulundu. Hastaların yaşı ortalama 71,82 $\pm 9,17$ yıl, $\mathrm{CHA}_{2} \mathrm{DS}_{2}$ ve $\mathrm{CHA}_{2} \mathrm{DS}_{2}$ VASc skorları sırasıyla $3,31 \pm 1,34$ ve $4,88 \pm 1,41$ idi. Hastaların $\% 43,8$ $(n=21)$ erkek, kalan \%56,2 $(n=27)$ kadın cinsiyete sahipti. Hastaların ayrıntılı demografik özellikleri Tablo1'de verilmiştir. Sadece 9 hasta $(\% 18,8)$ sigara kullanıyordu. Koroner arter hastalığı (KAH) 21 hastada $(\% 43,8)$, hipertansiyon (HT) 42 hastada $(\% 87,5)$ ve diyabetes mellitus 19 $(\% 39,6)$ mevcuttu. Hastaların \%27,1'inde (13 hastada) serebrovasküler olay (SVO) veya periferik emboli mevcuttu. Iki hastada $(\% 4,2)$ demans, 4 hastada $(\% 8,3)$ diğer nörolojik hastalıklar mevcuttu. Altı hastada $(\% 12,5)$ tiroid hastalığı vardı. Kanama hastaların \%14,6'sında $(n=7)$ gelişmişti, ancak hayatı tehdit eden veya kritik organ kanaması yoktu. AF tipi, 6 hastada paroksismal geri kalan $42(\% 87,5)$ hastada kalıcı idi. Tüm hastalar antikoagülan tedavi almaktaydı. Antikoagülan olarak 1 hastada enoksaparin, 7 hastada varfarin sodyum ve geri kalan 40 hastada non-vitamin $\mathrm{K}$ oral antikoagülan (NOAK) ajanlar kullanılmaktaydı. Kullanılan ortalama ilaç sayısı $5 \pm 1,1$ idi. Analize alınan 48 hastadan 42'si kliniğin düzenli takibinde idi ve ortalama takip süresi $2,46 \pm 1,2$ yıl idi.

İkinci olarak, hastaların böbrek fonksiyonlarının izlemde nası bir değişim gösterdiği araştıııldı. Ayrıntılı bilgi Tablo 2'de verilmiştir. Tüm hastaların aktüel (en son) kreatinin ve glomerüler filtrasyon oranı (GFR) düzeyleri mevcuttu ve bunlar sırasıyla 1,18 $\pm 0,28$ $\mathrm{mg} / \mathrm{dl}$ ve $56,19 \pm 16,90 \mathrm{ml} / \mathrm{dk}$ idi. Hastaların $\% 43,8$ 'inde $(n=21)$ ilk kreatinin ve GFR değeri de bulunmaktaydı. Bu hastalarda takip süresi boyunca kreatininde ılımlı bir yükselme ve GFR'de ılımlı bir düşme mevcuttu. Hastaların stabil ve dekompanse fazlardaki NT-proBNP düzeyleri ile bu düzeylerdeki değişimler Tablo 3'de verilmiştir. NT-proBNP dağılımı normal olmadığı için median, minimum ve maksimum değerleri kullanılmıştır. Hastaların stabil kronik fazda medyan NT-proBNP düzeyi 2039,50 pg/ml bulundu. Çalışmaya alınan 48 hastanın 15'inde hastaneye yatış gerektiren dekompansasyon gelişmişti ve dekompanse fazdaki medyan NTproBNP düzeyi $3093 \mathrm{pg} / \mathrm{ml}$ idi. Dekompansasyon ile ilişkili NT-proBNP düzeyindeki medyan artış $\% 91,34$ (minimum $\% 40,73$ ve maksimum $\% 246,52)$ bulundu. Korelasyon analizlerinde, NT-proBNP düzeyindeki değişim, yaş, SoVEF, kalp hızı, hemoglobin, $\mathrm{CHA}_{2} \mathrm{DS}_{2}$ ve $\mathrm{CHA}_{2} \mathrm{DS}_{2}$ VASc skorları ile korele bulunmadı. NT-proBNP düzeyindeki değişim ile sistolik kan basıncı $(r=0,66, p<0,05)$ ve sistolik pulmoner arter pasıncı $(r=0,73, p<0,05)$ arasında pozitif korelasyon mevcuttu.

\section{Tartışma}

Kalp yetersizliği, mortalite ve morbiditenin en önemli sebeplerinden biridir ve yaşla görülme sıklığı artmaktadır. Gelişmiş ülkelerde 70 yaşın üstündeki bireylerin $\geq \% 10$ 'unda KY olduğu bilinmektedir. Tedavideki gelişmeler, son 30 yılda özellikle DEF-KY hastalarında hastaneye yatışları azaltmış ve hayatta kalımı artırmıştır [1]. KY varlığı ve ciddiyetinin kantitatif bir göstergesi olan natriüretik peptidler (NP), KY tanısı ve tedavisinin takibinde birçok fayda sağlamaktadır. Klinik pratikte NT-proBNP ve BNP en sık kullanılan NP'lerdir ve benzer tanısal ve prognostik değere sahiptirler [11]. En son Avrupa kılavuzu, akut dispneli hastalarda KY tanısı için NP üst sınırlarını güncellemiştir. Son kılavuz, tanı koyma üst sınırlarını NT-proBNP için akut fazda yaşla ilişkili olarak, 50 yaştan genç, $50-75$ yaş ve 75 yaştan büyük hastalar 
Tablo 1. Tanımlayıcı demografikler.

\begin{tabular}{|c|c|c|}
\hline & $\mathrm{n}$ & Ortalama $\pm S S$ \\
\hline Yaş (yıl) & 48 & $71,82 \pm 9,17$ \\
\hline $\mathrm{CHA}_{2} \mathrm{DS}_{2}$ & 48 & $3,31 \pm 1,34$ \\
\hline $\mathrm{CHA}_{2} \mathrm{DS}_{2} \mathrm{VASc}$ & 48 & $4,88 \pm 1,41$ \\
\hline Sistolik KB (mmHg) & 48 & $143,73 \pm 24,47$ \\
\hline Diyastolik KB (mmHg) & 48 & $84,06 \pm 14,15$ \\
\hline Kalp Hızı (atım/dakika) & 48 & $85,90 \pm 20,18$ \\
\hline SoVEF (\%) & 48 & $35,42 \pm 3,75$ \\
\hline SoAÇ (mm) & 48 & $51,94 \pm 4,00$ \\
\hline Triküspid Anulus (mm) & 43 & $40,19 \pm 4,49$ \\
\hline SPAP $(\mathrm{mmHg})$ & 48 & $42,26 \pm 8,51$ \\
\hline Hemoglobin (g/dl) & 48 & $13,12 \pm 1,95$ \\
\hline Hematokrit (\%) & 48 & $40,29 \pm 5,37$ \\
\hline Trombosit $\left(10^{3} / \mathrm{mm}^{3}\right)$ & 48 & $227,2 \pm 65,2$ \\
\hline AKŞ (mg/dl) & 48 & $117,5 \pm 32,1$ \\
\hline $\mathrm{HDL}(\mathrm{mg} / \mathrm{dl})$ & 47 & $49,85 \pm 14,10$ \\
\hline LDL (mg/dl) & 45 & $97,07 \pm 34,69$ \\
\hline $\mathrm{TG}(\mathrm{mg} / \mathrm{dl})$ & 47 & $127,51 \pm 82,78$ \\
\hline Üre (mg/dl) & 48 & $43,90 \pm 16,05$ \\
\hline Kreatinin (mg/dl) & 48 & $1,18 \pm 0,28$ \\
\hline $\mathrm{Na}(\mathrm{mmol} / \mathrm{L})$ & 48 & $141,50 \pm 2,67$ \\
\hline $\mathrm{K}(\mathrm{mmol} / \mathrm{L})$ & 47 & $4,43 \pm 0,43$ \\
\hline Ürik Asit (mg/dl) & 36 & $6,80 \pm 1,57$ \\
\hline GFR (ml/dk) & 48 & $56,19 \pm 16,90$ \\
\hline $\mathrm{TSH}(\mathrm{mU} / \mathrm{L})$ & 48 & $1,55 \pm 1,40$ \\
\hline \multicolumn{3}{|l|}{ Takip Süresi (YIL) } \\
\hline$>3$ YII n=16, \%38,1 & 42 & $2,46 \pm 1,26$ \\
\hline$>5 Y_{I} \mid n=1, \% 2,4$ & & \\
\hline
\end{tabular}

Çalışmaya alınan hastaların klinik ve laboratuvar özellikleri tabloda verilmiştir. Tablodaki $n$, hasta sayısını göstermektedir. Kısaltmalar: $\mathrm{SS}=$ standart sapma, $\mathrm{KB}=\mathrm{kan}$ basıncı, SoVEF= sol ventrikül ejeksiyon fraksiyonu, SoAÇ= sol atriyum çapı, SPAP = sistolik pulmoner arter basıncı, $A K S ̧=$ açlık kan şekeri, $H D L=$ yüksek dansiteli lipoprotein, $L D L=$ düşük dansiteli lipoprotein, $\mathrm{TG}=$ trigiserid, $\mathrm{Na}=$ sodyum, $\mathrm{K}=$ potasyum, $\mathrm{GFR}=$ glomerüler filtrasyon oranı, $\mathrm{TSH}=$ tiroid stimülan hormon 
Tablo 2. Hastaların izleminde böbrek fonksiyonlarındaki değişimler.

\begin{tabular}{lll}
\hline & $\mathrm{n}$ & ortalama \pm SS \\
\hline İlk Kreatinin $(\mathrm{mg} / \mathrm{dl})$ & 21 & $1,29 \pm 0,62$ \\
Aktuel Kreatinin $(\mathrm{mg} / \mathrm{dl})$ & 48 & $1,18 \pm 0,28$ \\
$\circ$ Kreatinin $(\mathrm{mg} / \mathrm{dl})$ & 21 & $-0,17 \pm 0,64$ \\
İlk GFR $(\mathrm{ml} / \mathrm{dk})$ & 21 & $60,46 \pm 16,83$ \\
Aktuel GFR $(\mathrm{ml} / \mathrm{dk})$ & 47 & $56,19 \pm 16,9$ \\
$\circ$ GFR $(\mathrm{ml} / \mathrm{dk})$ & 21 & $-4,77 \pm 13,8$ \\
\hline
\end{tabular}

Çalışmaya alınan hastaların hastane kayıt sistemindeki klinik geçmişlerinde 21 hastada kliniğe ilk kez başvuru yaptıkları döneme ait kreatinin ve GFR değerleri mevcuttu. Hastaların ilk ve son kreatinin ve GFR düzeyleri ile izlemdeki değişiklikler ortaya kondu.

Kısaltmalar: SS= standart sapma, GFR= glomerüler filtrasyon oranı

Tablo 3. Hastaların NT-proBNP düzeyleri ve izlemdeki değişimler.

\begin{tabular}{lllll}
\hline & $\mathrm{n}$ & Median & Minimum & Maksimum \\
\hline $\begin{array}{l}\text { Kompanse } \\
\text { NT-proBNP }(\mathrm{pg} / \mathrm{ml})\end{array}$ & 48 & 2039,50 & 240,00 & 17000,00 \\
$\begin{array}{l}\text { Dekompanse } \\
\text { NT-proBNP }(\mathrm{pg} / \mathrm{ml})\end{array}$ & 15 & 3093,00 & 1489,00 & 12705,00 \\
$\circ$ NT-proBNP $(\mathrm{pg} / \mathrm{ml})$ & 15 & 1571,50 & & \\
$\circ$ NT-proBNP $(\%)$ & 15 & 91,34 & 791,00 & 8935,00 \\
\hline
\end{tabular}

Çalışmaya alınan hastaların tümünde stabil fazda NT-proBNP düzeyi ve 15 hastada ise hastane kayıt sistemindeki klinik geçmişlerinde dekompansasyona ait NT-proBNP düzeyi mevcuttu. Hastaların kompanse ve dekompanse fazlardaki NTproBNP düzeyleri ve NT-proBNP'deki fazlar arasındaki değişim ve bu değişimin yüzdesi verildi. NT-proBNP, istatistiksel olarak normal dağılmadığından medyan, minimum ve maksimum değerler kullanıldı.

Kısaltma: NT-proBNP= N-terminal pro-B tip natriüretik peptid

için sırasıyla 450, 900 ve $1800 \mathrm{pg} / \mathrm{ml}$ olarak tanımlamıştır. Yaştan bağımsız olarak akut dispneli hastalarda $300 \mathrm{pg} / \mathrm{ml}$ ve akut olmayan dispneli hastalarda $125 \mathrm{pg} / \mathrm{ml}$ düzeylerinin altı KY tanısını dışlamak için önerilmektedir [11]. AF, KY'de SoVEF'den bağımsız olarak en sık görülen ritm bozukluğudur. AF, tromboembolik komplikasyonlarla olduğu kadar, kardiyak fonksiyonlarda bozulma ve semptomların kötüleşmesi ile de ilişkilidir. KY ile birlikte AF olan hastalar, en 'hasta' gruptur ve en kötü sonlanımlara sahiptir $[1,8]$. AF ve $\mathrm{KY}$ birlikte var olduğu hastalar, klinisyen için karar vermesi oldukça zor bir gruptur çünkü KY'den bağımsız olarak da AF'da NP düzeylerinin yüksek olduğu bilinmektedir [11, 15]. Hem AF hem de KY varlığında NP üst sınırın daha yüksek olduğu düşünülse de üst sınııın ne olması gerektiği konusunda bir fikir birliği yoktur. Klinik pratikte çok önem taşıyan diğer bir konuda kalp ve böbrek fonksiyonları arasındaki ilişkidir. Kronik KY olan ayaktan hastaların yaklaşık üçte birinde böbrek fonksiyon bozukluğu da mevcuttur [16].
Böbrek fonksiyon bozukluğu da NP düzeylerini arttıran bir durumdur. Elimizdeki veriler böbrek fonksiyon bozukluğunda görülen NP artışının sadece azalmış renal klirensle ilişkili olmadığını, kalp ve böbrek arasındaki karmaşık regülatör mekanizmaları içeren multifaktöryel bir etyoloji ile ilişkili olduğunu düşündürmektedir [11, 17, 18]. NP ile $K Y$ tanısı koyarken, optimal tanısal etkinliği korumak için GFR $<60 \mathrm{~mL} / \mathrm{dk}$ olduğunda $K Y$ için üst sınır değerlerinin arttırılması gerekebilir [11, 18]. Ancak, yaş ve GFR arasındaki yakın ilişki bilindiğinden, NT-proBNP için yaş bağımlı üst sınır değerleri kullanıldığında ilave bir düzeltme gerekmeyebilir. Bununla birlikte kardiyak ve renal hastalıklar arasındaki güçlü ilişki göz önüne alınarak, böbrek yetmezliği olan hastalarda da yüksek NP düzeylerinin kardiyak hastalığı düşündürmesi ve klinik karar verme sürecinde dikkate alınması önerilir [11].

NT-proBNP düzeylerinin AF'da yüksek olduğu bilinmekle beraber, bu yükselmenin ne kadarından AF'un, ne kadarından KY'nin 
sorumlu olduğu son zamanlarda araştırıcıların ilgisini çeken önemli bir konudur. Bununla ilgili olası bazı açıklamalar mevcuttur. Öncelikle NT-proBNP artışı, AF atağı esnasındaki hemodinamik değişiklikler ile ilgili olabilir. Ayrıca, uzun süreli AF'un sebep olduğu kronik yapısal veya işlevsel kardiyak remodelling, artmış NT-proBNP düzeylerine yol açabilir. En son olarak da artmış NT-proBNP düzeyleri, AF olan KY hastalarının daha ileri bir KY'e sahip olduğunu yansıtıyor da olabilir. Santema ve arkadaşlarının yaptığı son çalışmada DEFKY olan hastalarda NT-proBNP düzeylerinin eşlik eden AF bulunması durumunda anlamlı olarak yüksek olduğunu göstermiştir [19]. Yazarlar, BIOSTAT-CHF çalışmasının bir posthoc analizini yapmışlar ve SoVEF $\leq \% 40$ olan KY hastalarında dekompanse fazda medyan NT-proBNP düzeyini $A F$ varlığında ve $A F$ yokluğunda sırasıyla $3417 \mathrm{pg} / \mathrm{ml}$ ve $1588 \mathrm{pg} / \mathrm{ml}$ bulmuşlardır [19, 20].

Günlük pratikte $D E F-K Y$ ile $A F$ beraber bulunduğu hasta grubu, bizim çalışma grubumuzun da temsil ettiği, daha yaşlı, ılımlı böbrek yetmezliği olan ve yüksek risk skorlarıyla karakterize oldukça 'hasta' bir gruptur ve bu hastaların yönetimi çok daha zordur. Bu hasta grubu ne yazık ki kılavuzlarda ayrıntılı olarak tanımlanmamıştır ve özellikle bu gruptaki NP düzeyleri ile ilgili bir konsensus yoktur. Bu hastalarda düşük ejeksiyon fraksiyonu, aritmi ve renal disfonksiyon, multifaktöriyel komplike mekanizmalar ile birbirini etkileyerek beklenenin üzerinde NP düzeylerine sebep olmaktadır. Bizim çalışmamızdaki DEF-KY ve AF hastaları, ortalama yaşı $71,82 \pm 9,17$ yıl, $\mathrm{CHA}_{2} \mathrm{DS}_{2}$ ve $\mathrm{CHA}_{2} \mathrm{DS}_{2}$ VASc skorları sırasıyla $3,31 \pm 1,34$ ve $4,88 \pm 1,41$, ortalama GFR değeri $56,19 \pm 16,90$ olan ve SoVEF \%35,42 $\pm 3,75$ bulunan, yüksek riskli bir gruptu. Bu grubun kronik stabil fazdaki medyan NT-proBNP düzeyi 2039,50 pg/ml ile NP kılavuzunda KY tanısı için önerilen üst sınırların çok üzerinde idi. Çalışmaya alınan 48 hastanın 15 'inde hastaneye yatış gerektiren dekompansasyon mevcuttu ve dekompanse fazdaki medyan NT-proBNP düzeyi de 3093 $\mathrm{pg} / \mathrm{ml}$ bulundu. Dekompanse fazdaki bu düzey en son literatür ile uyumlu olmasına rağmen bu değer de son NP kılavuzundaki önerilen üst sınırların çok üzerindedir ve bu hastaların daha farklı olarak ele alınması gerektiğini düşündürmektedir [11, 19]. Bizim çalışmamızın literatüre en önemli katkısı, NP üst sınırı için bir konsensus olmayan DEF-KY ve AF bulunan hastalarda (eşlik eden ılımlı böbrek yetmezliği ile beraber), stabil kronik fazdaki ortalama NTproBNP düzeyleri ile ilgili bir fikir vermesi, bu hastalarda dekompansasyon tanısı için standart üst sınırların yeterli olmadığını düşündürmesidir. Ayrıca, hastanın stabil kronik fazdaki NTproBNP değerinin bilinmesinin, ilerleyen dönemlerde gelişen dispnede dekompansasyon veya nonkardiyak etyolojinin belirlenmesi adına çok önemli olduğunun da altı çizilmelidir. Bu yüksek riskli hasta grubunda, her hastanın kendi stabil faz ve dekompansasyon sınırlarının bilinmesi, bireyselleştirilmiş tedavinin temelini oluşturmaktadır.

Çalışmamızın bazı sınırlamaları vardır. En önemli sınırlama düşük hasta sayısıdır, ancak DEF-KY ile AF birlikteliği genelde en 'hasta' grubu temsil ettiğinden günlük pratikte de bu hastalar KY hastalarının daha küçük bir kısmını oluşturmaktadır. Çalışmaya sinüs ritminde olan DEF-KY hastalarının alınmaması diğer önemli bir kısıtlamadır çünkü bu iki grubun karşılaştırılması AF'nin NT-proBNP üzerindeki etkisini belirlemeye daha fazla yardımcı olabilir Her ne kadar kapalı bir kohortun verisi kullanılsa da retrospektif tasarım diğer bir sınırlamadır, çünkü bazı hastalar dekompanse fazda başka sağlık kurumlarına başvurmuş olabilirler. Bütün bunlara rağmen çalışmamız, günlük pratikte hepimizi zorlayan ve üzerinde fikir birliği olmayan bir hasta grubuna farklı bir bakış açısı getirmektedir.

Sonuç olarak, günlük klinik pratikte karşılaşı̆̆ı̆ımız tipik yüksek riskli grup olan daha yaşlı, ılımlı böbrek yetersizliği bulunan, skoru yüksek ve AF'un eşlik ettiği DEF-KY hastalarının takibi oldukça zordur ve bu hastalardaki NP düzeyleri izole DEF-KY hastalarının çok üzerindedir. Bireyselleştirilmiş tedavi, kılavuzlarda geniş bir şekilde ele alınmayan bu grupta gereklidir ve bunun bir parçası olarak bu hastaların stabil fazdaki NP düzeylerinin bilinmesi klinisyene karar verme sürecinde yardımcı olacaktır.

Çıkar ilişkisi: Tüm yazarlar çıkar ilişkisi olmadığını beyan eder. 


\section{Kaynaklar}

1. Ponikowski P, Voors AA, Anker SD, et al. 2016 ESC Guidelines for the diagnosis and treatment of acute and chronic heart failure: the Task Force for the diagnosis and treatment of acute and chronic heart failure of the European Society of Cardiology (ESC) Developed with the special contribution of the Heart Failure Association (HFA) of the ESC. Eur Heart J 2016;37:2129-2200. https://doi.org/10.1093/eurheartj/ ehw128

2. McMurray JJV. Clinical practice. Systolic heart failure. $\mathrm{N}$ Engl J Med 2010;362:228-238. https://doi.org/10.1056/ NEJMcp0909392

3. Chen J, Normand SLT, Wang Y, Krumholz HM. National and regional trends in heart failure hospitalization and mortality rates for Medicare beneficiaries, 1998-2008. JAMA 2011;306:1669-1678. https://doi.org/10.1001/ jama.2011.1474

4. Dunlay SM, Redfield MM, Weston SA, et al. Hospitalizations after heart failure diagnosis: a community perspective. J Am Coll Cardiol 2009;54:1695-1702. https://doi.org/10.1016/j. jacc.2009.08.019

5. Gerber Y, Weston SA, Redfield MM, et al. A contemporary appraisal of the heart failure epidemic in Olmsted County, Minnesota, 2000 to 2010. JAMA Intern Med 2015;175:996-1004. https://doi.org/10.1001/ jamainternmed.2015.0924

6. Owan TE, Hodge DO, Herges RM, Jacobsen SJ, Roger $\mathrm{VL}$, Redfield MM. Trends in prevalence and outcome of heart failure with preserved ejection fraction. $\mathrm{N}$ Engl J Med 2006;355:251-259. https://doi.org/10.1056/ NEJMoa052256

7. Maggioni AP, Dahlstro "m U, Filippatos G, et al. EURObservational Research Programme: regional differences and 1-year follow-up results of the Heart Failure Pilot Survey (ESC-HF Pilot). Eur J Heart Fail 2013;15:808-817. https://doi.org/10.1093/eurjhf/hft050

8. Kirchhof P, Benussi S, Kotecha D, et al. 2016 ESC Guidelines for the management of atrial fibrillation developed in collaboration with EACTS. Eur Heart J 2016;37:2893-2962. https://doi.org/10.1093/eurheartj/ ehw210

9. Swedberg K, Olsson LG, Charlesworth A, et al. Prognostic relevance of atrial fibrillation in patients with chronic heart failure on long-term treatment with beta- blockers: results from COMET. Eur Heart J 2005;26:1303-1308. https://doi.org/10.1093/eurheartj/ ehi166

10. Hoppe UC, Casares JM, Eiskjaer H, et al. Effect of cardiac resynchronization on the incidence of atrial fibrillation in patients with severe heart failure. Circulation 2006;114:18-25. https://doi.org/10.1161/ CIRCULATIONAHA.106.614560
11. Mueller C, McDonald K, de Boer RA, et al. Heart Failure Association of the European Society of Cardiology practical guidance on the use of natriuretic peptide concentrations. Eur J Heart Fail 2019;21:715-731. https://doi.org/10.1002/ejhf.1494

12. Januzzi JL, Chen-Tournoux AA, Christenson RH, et al. N-terminal pro-B-type natriuretic peptide in the Emergency Department: the ICON-RELOADED Study. J Am Coll Cardiol 2018;71:1191-1200. https://doi. org/10.1016/j.jacc.2018.01.021

13. Ibrahim I, Kuan WS, Frampton C, et al. Superior performance of $\mathrm{N}$-terminal pro brain natriuretic peptide for diagnosis of acute decompensated heart failure in an Asian compared with a Western setting. Eur J Heart Fail 2017;19:209-217. https://doi.org/10.1002/ejhf.612

14. Morello A, Lloyd-Jones DM, Chae CU, et al. Association of atrial fibrillation and amino-terminal pro-brain natriuretic peptide concentrations in dyspneic subjects with and without acute heart failure: results from the ProBNP investigation of dyspnea in the Emergency Department (PRIDE) study. Am Heart J 2007;153:9097. https://doi.org/10.1016/j.ahj.2006.10.005

15. Richards M, Di Somma S, Mueller C, et al. Atrial fibrillation impairs the diagnostic performance of cardiac natriuretic peptides in dyspneic patients: results from the BACH Study (Biomarkers in ACute Heart Failure). JACC Heart Fail 2013;1:192-199. https://doi. org/10.1016/j.jchf.2013.02.004

16. Dries DL, Exner DV, Domanski MJ, Greenberg B, Stevenson LW. The prognostic implications of renal insufficiency in asymptomatic and symptomatic patients with left ventricular systolic dysfunction. J Am Coll Cardiol 2000;35:681-689. https://doi.org/10.1016/ s0735-1097(99)00608-7

17. Hogenhuis J, Voors AA, Jaarsma T, et al. Anaemia and renal dysfunction are independently associated with BNP and NT-proBNP levels in patients with heart failure. Eur J Heart Fail 2007;9:787-794. https://doi. org/10.1016/j.ejheart.2007.04.001

18. McCullough PA, Duc P, Omland T, et al. B-type natriuretic peptide and renal function in the diagnosis of heart failure: an analysis from the breathing not properly multinational study. Am J Kidney Dis 2003;41:571-579. https://doi.org/10.1053/ajkd.2003.50118

19. Santema BT, Chan MM, Tromp J, et al. The influence of atrial fibrillation on the levels of NT-proBNP versus GDF-15 in patients with heart failure. Clin Res Cardiol Published online 01 July 2019. https://doi.org/10.1007/ s00392-019-01513-y

20. Voors AA, Anker SD, Cleland JG, et al. BIOlogy Study to tailored treatment in chronic heart failure: rationale, design and baseline characteristics of BIOSTATCHF. Eur J Heart Fail 2016;18:716-726. https://doi. org/10.1002/ejhf.531 
Etik uyum: Bu çalışma, retrospektif bir arşiv tarama çalışması olarak planlandı ve hiçbir maddi destek almadı. Çalışmanın etik onamı, Sağlık Bilimleri Üniversitesi, İzmir Tepecik Sağlık Uygulama Araştırma Merkezi Girişimsel Olmayan Etik Kurulu'ndan 14.11.2018 tarih ve 2018/13-13 karar numarası ile alındı.

Teşekkür: Çalışmanın istatistikleri konusunda yardımları için İstatistik Danışmanı sayın Ömer Kaplan'a teşekkür ederiz. 